\title{
A REVIEW: DEVELOPMENT OF TESTING DEVICE FOR THE CONVEYOR SYSTEM USING AUTOMATION
}

\author{
Paresh M.Waghamare ${ }^{1}$, Sachin Gawate ${ }^{2}$ \\ ${ }^{I}$ M.E.Student, Department of Computer Science \& Engineering, G.H.Raisoni College of Engineering, Nagpur, India \\ ${ }^{2}$ Assistant Professor, Department of Computer Science \& Engineering, G.H.Raisoni College of Engineering, Nagpur, \\ India
}

\begin{abstract}
This Paper Focused on the testing device i.e. conveyor system for the quality control department using automation (PLC \& SCADA). The paper belongs to the different sections such as how the conveyor system works on PLC. Second thing how the system handles the section of motors i.e. D.C. motors, solenoid etc. Third thing is the most important how it will handles the faults detected in the conveyor system and gives us the fault free output. The main goal of the project is to reduce the errors in the product size. The conveyor system also deals with the monitoring structure i.e. SCADA part of the system. SCADA gives you the visualisation structure that's makes easy to handle the system and error free output. The solenoid connects in the project will ejects the faulty material and gives you the suitable material or product.
\end{abstract}

Keywords: PLC (Programmable Logic Controller), SCADA (Supervisory Control And Data Acquisition System), Conveyor System, Solenoid.

\section{INTRODUCTION}

\subsection{Programmable Logic Controller (PLC)}

PLC is a special type of computer system used to handle the various operations such as on/off control, sequencing, timing, counting, and arithmetic operation etc. generally PLC's are used in almost every aspect of industry purpose to expand and enhance the production. In earlier conventional system number of electromechanical devices is used to perform certain functions, but a single PLC can be used a replacement for all these type of devices. Due to these special functions of PLC, it will provide many advantages over these relay type of devices such as flexibility, low cost, communication capability, faster response time etc.

PLC is a microcontroller based device consists of input sensing devices as well as output sensing devices. The input devices include the status of field connected sensors and the output devices include the actuators such as motors, starters, solenoids, speed drives etc. The major difference between the PLC and other microcontroller is that it will extensively use in the severe conditions like hot and humid temperature, cold conditions etc as compared to the other microcontroller. Again, the PLC consist of CPU i.e. central processing unit, memory i.e. programme and data similar to the other microcontrollers. Typically, the PLC works on the 230v AC supply or $24 \mathrm{v}$ DC supply. The user can use the suitable power supply as per the required conditions. The PLC's are connecting with the communicating devices i.e. PC (personal computer) to access the commands given by the user to operate the various output parameters.
In any PLC system, there are few basic components i.e.

- The PLC Processor or controller

- I/O (input/output) modules.

- Chassis or backplane.

- Power supply.

- Programming software that runs in a PC.

- Network Interface.

PLC Processor or Controller: - In PLC the processor plays an important role to perform the several functions in industrial area. The processor is the heart of any PLC. Without a processor one cannot control the operations related to industrial applications. Generally a processor might be 32 Bit or 64 Bit as well. It only depends on the how much memory one will required to perform the operation.

Input/output modules: - I/O modules consist of different elements which will indicate or given by user. The input module can be assigned or modified by the user as per the requirement. Output module will be the replica of input operations perform by the user.

Chassis or backplane: - The chassis or backplane is the outer structure of PLC. As mentioned earlier in the introduction part of PLC, these PLC's are operate in the severe conditions weather it would be hot and humid, cold etc. The chassis or backplane gives the protection to the PLC in these types of severe conditions.

Power Supply: - The power supply required to energies the PLC is either 230v AC or 24v DC supply. If the operation is in lower range industrial area which works on the DC power supply can use up to the $24 \mathrm{v}$ DC supply. And if the 
operation is above the large and high scale industrial area then these takes the power of $230 \mathrm{v}$ AC supply for the operation.

Programming Software: - The programming software required to check the input as well as output status of the PLC is different for the different PLC's. This will be depends on the manufactures of the PLC. E.g. the Allen Bradley PLC will use the RSLinx software for the communication with the PLC. The user can give the commands as well as he can check the input status of the PLC.

\section{Block diagram for PLC:-}

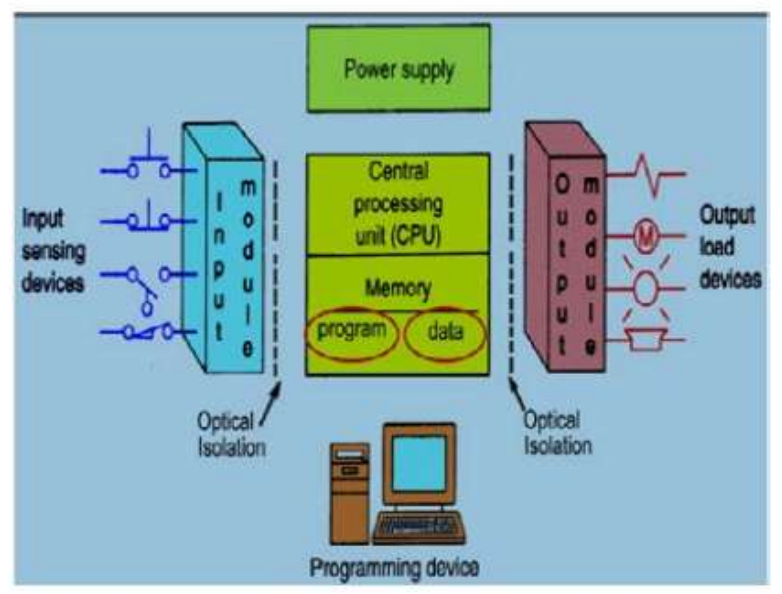

Fig 1: Block diagram of PLC

\subsection{Supervisory Control and Data Acquisition (SCADA)}

SCADA is the monitoring or visualising software for the PLC which the user is working. SCADA is used the serial communication i.e. RS 232 for communication with the PLC. it takes the user oriented commands for communication and it also shows the graphical representation for the same. The user made the connection with the PLC and SCADA to operate the different operations. Whichever the input commands you will give to the PLC that will be modified and gets corrected in the SCADA software.

The below figure will shows the actual interfacing with the SCADA and PLC.



Fig 1.1: Interfacing of SCADA with PLC

\subsection{The Conveyor System}

The conveyor system consists of Conveyor belt and the sensing elements which will give the exact value for the operation of the conveyor system. The Conveyor belt is used in the various industries to circulate the materials (such as plastic bottles, metal tins, coal in power plant etc.) but in our proposed system, the conveyor belt is used for passing the metal tins. The sensors such as proximity sensor 1, proximity sensor 2 , and sensor 3 are used to check the uniformity of the material passing on the conveyor belt.

The Sensors which are used in the proposed system will listed below.

- $\quad$ Sensor 1:- Detecting Element (Optical Sensor).

- Sensor 2:- Detecting Element (Proxy Sensor, inductive type, 2-3 $\mathrm{mm}$ range).

- Sensor 3:- Used as Ejector (to reject the defective element).

- Sensor 4:- Detecting Element (Proxy Sensor, 5-7 mm range).

The below Figure shows the Schematic Structure of Conveyor System.

\section{Proximitysensor1 Sensor2 Ejector Sensor4}

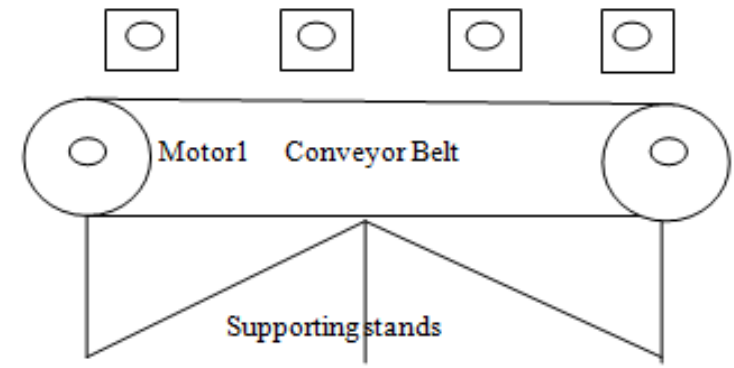

Fig 1.2: Schematic Structure of Conveyor System

\section{Components of Conveyor System}

- Conveyor Motor

- Conveyor mechanical structure

- Gear and Pulleys coupled with motor.

- Sensing elements as per the goods transported on the conveyor belt.

- An Ejector (solenoid valve) to remove detective goods from the belt, so that only the good quality pieces are gathered.

Use of $12 \mathrm{~V}$ DC geared motor which will drive the conveyor belt unit. The products/goods are passed on the belt. Various detecting elements for respective operations will be installed on the conveyor belt. They will perform the operation as per the requirement. The programme in the Controller (PLC) is designed accordingly to execute the automatic operation. The SCADA is interfaced with the controller in order to analysis the executed operation. Further need of improvement in the mechanism will be considered depending on the data compiled through acquisition system. This will improve the efficiency of the production unit. Strategies can also be modified based on the data available. 


\section{LITERATURE SURVEY}

The literature review of any project will gives the exact replica of project work done. The following survey will gives the clear approach or research work for the project.

R.Keerthika, M.Jagadeeswari [1]: - In this paper the author exclusively deals with the coal conveyor belt in the coal handling in thermal power plant. The coal conveyor belt in the thermal power plant is controlled, processed, and monitored through the PLC \& SCADA.

Anup dakre, Junaid G.Sayed, Ekta A.Thorat, Aouruf Ahemad md.Aves Choudhary [2]:- this paper deals with the implementation of bottle fill system through PLC and SCADA. The bottles on the conveyor belt are moving one by one simultaneously and filled with some short span of time. The PLC takes the command given by the controller and will gives the visualisation through the software called as SCADA.

Ashwini Bhivgade [3]:- The author of this paper focuses on the automation of conveyor through the PLC. Here PLC i.e. programmable logic controllers will the major part of the proposed system. PLC actually commands and controls the action taking for conveyor system. The conveyor moves automatically by the programmed controller of PLC.

K.Thiyagarajan, Meenakshi R, Sugmaya P [4]:- The human eyes will come into the picture when the vision word describes. The classification of the bottles \& filling system on the conveyor system done by the human vision. The eyes will actually works for this type of system. The conveyor automatically move along with the human eyes are in contact. After filling one bottle another bottle will filled with some short span of time.

D.S.V. Siva vardhan, Y.Shivraj Narayan [5]:- This paper takes the light on the development of monitoring and controlling the objects on the conveyor system. Again, the monitoring is done through the software called SCADA. These only monitors the object on the conveyor belt and will indicates through the software graphically.

Chen Xu Hui, MD Lutfar, Rahaman, and Zhang Yin [6]:The paper focuses on the speed control of DC conveyor system through Fuzzy logic. The fuzzy will gives the actual or probable result of the system. As in this paper, the speed of the DC conveyor belt will be controlled i.e. the classes or the sets of speed will be made and the possible optimal solution will takes from these sets. The fuzzy system is the technique of artificial intelligence that made the system more accurate and reliable. The conveyors in the plants should give the accurate value in the sense of speed. The PID controller will used in this research work.

Chitra.s, Vijaya Raghvan [7]:- This paper also focuses on the conveyor control using PLC.PLC made the works east and accurate. The industrial automation will control by the major part of the PLC. PLC will automatically set the value and gives the user a suitable and actual data which is required to operate the system.

Tard Heljing, Beegat Lannarstau [8]:- The discrete values in the nature are complex to handle. The conveyor system will provide the analog as well as discrete value in nature to handle the complex task in the industrial automation process. The process will be simple or either complex in nature.

\section{PROPOSED METHODOLOGY}

Flow graph for the Proposed System.

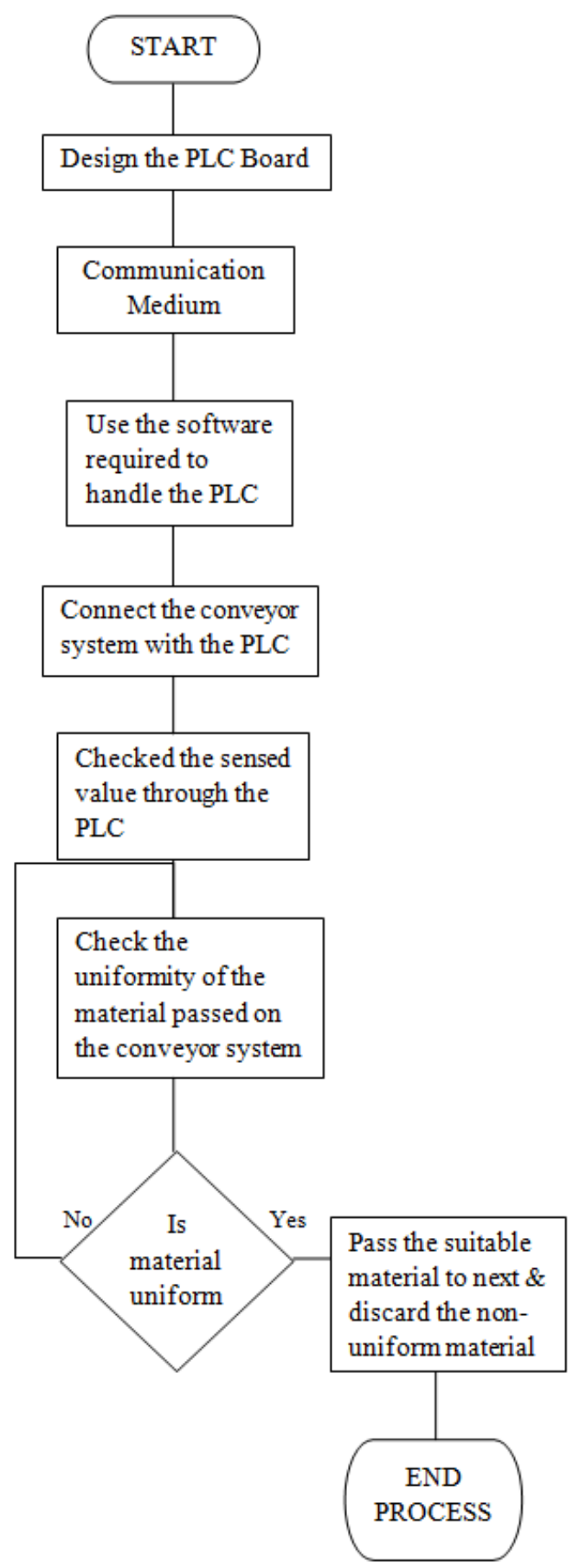

Fig 3: - Flow graph of Proposed System 
The above flow graph will indicates the actual proposed system. The steps required to initialise the project will be stated as below

Step I: - Start the process for design of the PLC i.e. programmable Logic Controller.

Step II: - The communication medium.

Step III: - The software which is required to monitor the PLC i.e. RSLinx.

Step IV: - Attached the conveyor system with the PLC and the software resp.

Step V: - The sensor which is connected with the conveyor system gives some sensed values which is to be checked.

Step VI:-The main party of the project i.e. check the uniformity of the material passed or circulates on the conveyor system.

Step VII: - The important function whether the product or goods passing on the conveyor system is uniform or nonuniform in nature.

Step VIII: - If the material or goods on the conveyor belt is OK i.e. valid then it will be moved on the further process or the faulty material gets discarded.

These above steps are much important to handle the device called conveyor system in any plant and this is need for industrial automation.

\section{WORKING OF THE SYSTEM}

The system proposes a simple way to handle the conveyor system to gives you the suitable product/material needs in industrial area. Day by day industry needs the automatic handling the system and reduce the manpower to increases the profit. The system handles with the PLC and SCADA improves the visualisation. As the conveyor rolls with the help of motors at the front as well as back end which improves the smooth rolling of the conveyor. The electromechanical device i.e. relays which handles the power through the device. As conveyor rolls the material on the conveyor move with the conveyor and detects through the sensor which indicates in the fig $1.12 \mathrm{c}$ named as the primary sensor. Again it will move forward through the other sensor the second sensor respectively. The third sensor which acts as an ejector which ejects the faulty product on the conveyor system and pass the suitable product for the next process and finally the last sensor will gives the fault free output. The system is connected to the PLC system which takes the commands through PLC. The programme burns in the controller of the PLC which uses the ladder programming which is the easiest way to programme the PLC for industrial automation. The commands need to handle the PLC in proper way. The SCADA which also connect with the system gives the exact visualisation which handles the conveyor system.

\section{CONCLUSION}

The conveyor system monitored, controlled with the help of Programmable Logic Controller, SCADA and various sensors. In many plants the conveyor plays an important role to move material and various parts from one place to other. In point of reducing human errors the PLC i.e. programmable logic controller and SCADA are important to design and highly reliable system. SCADA is used for real time monitoring thus proposed system gives better accuracy, time consuming, low power consumption etc.

\section{REFERENCES}

[1]. R.Keerthika, M.Jagadeeswari (2015) "Coal Conveyor Belt Fault Detection and Control in Thermal power plant using PLC and SCADA", Internantional Journal of advance research in computer engineering \& technology Volume 4 Issue 41

[2]. Anup dakre, Junaid G.Sayed, Ekta A.Thorat, Aouruf Ahemad md.Aves Choudhary (2015)"Implementation of bottle filling and capping using plc with scada", International research journal of engineering \& technology Volume 2 Issue 09.

[3]. Ashwini Bhivgade (2015) "Automation of Conveyor using PLC", International Journal of current emerging and scientific research, ISSN (print): 2393-8374, (online): 23940697, Volume-2, Issue-4.

[4]. K.Thiyagarajan, Meenakshi R, Sugmaya P(2016) "Vision based bottle classification and automatic bottle filling system" International Conference on Advances in Human Machine Interaction (HMI - 2016), March 03-05.

[5]. D.S.V. Siva vardhan, Y.Shivraj Narayan (2015) "Development of an Automatic Monitoring and Control System for the Objects on the Conveyor Belt" International Conference on Man and Machine Interfacing.

[6]. Chen Xu Hui, MD Lutfar, Rahaman, and Zhang Yin (2016) "Adaptive Fuzzy PID Speed Control of DC Belt Conveyor System” IEEE SNPD 2016, May 30-June 1.

[7]. Chitra.s, Vijaya Raghvan (2014)“Conveyor Control Using Programmable Logic Controller" International Journal of Advancements in Research \& Technology, Volume 3, Issue 8.

[8]. Tard Heljing, Beegat Lannarstau (2012) "Sensor Graphs for Discrete Event Modelling Applied to Formal Verification of PLCs" IEEE transactions on control systems technology, vol. 20, no. 6 . 